\title{
Bridges Baltimore 2015: Charmed by Mathematics in Charm City
}

\author{
Kristóf Fenyvesi ${ }^{1}$ (D)
}

Published online: 8 February 2016

(C) Kim Williams Books, Turin 2016

\begin{abstract}
In 2015, the Bridges World Conference, the most significant annual international gathering to be held for exploring connections between mathematics and the arts, met in Baltimore, USA. The conference program included lectures by recognized scholars and artists, the world largest exhibition of mathematical art, thematic theatre performances, a poetry afternoon demonstrating how mathematics can interrelate with literature, and a short film festival as well as workshops organized by researchers, educators and artists.
\end{abstract}

Keywords Bridges conference $\cdot$ Baltimore $\cdot$ Mathematics $\cdot$ Arts

In 2015, the Bridges Conference, the most significant annual international gathering for exploring connections between mathematics and the arts, met in Baltimore, USA. The conference program included lectures by recognized scholars and artists, the world largest exhibition of mathematical art, thematic theatre performances, a poetry afternoon demonstrating how mathematics can interrelate with literature, and a short film festival as well as workshops organized by researchers, educators and artists. Last but not least, on Family Day Bridges opened its doors to a broader audience, drawing all those interested in gaining a deeper yet playful perspective on mathematics and its multitude of creative applications.

Although Baltimore, the largest city in Maryland, first hosted the Bridges conference in 2015, the Bridges community had the opportunity to visit this area twice before. When Towson, a university town situated next to Baltimore, provided

Kristóf Fenyvesi

fenyvesi.kristof@gmail.com

1 Department of Art and Culture Studies (TAIKU), University of Jyväskylä, PO Box 35, 40014 Jyväskylä, Finland 
the venue for the conference in 2002 and 2012, Baltimore's rich past and diverse cultural programs made it only natural for this to be the destination for the Bridges thematic excursions. As of 2012, regular conference participants have been able to experience the Walters Museum's varied collection and main historical scientific attraction, the Archimedes Palimpsest (see http://www.archimedespalimpsest.org/), enjoy the world's largest Matisse collection at the Baltimore Museum of Art, or be exposed to American outsider art at its citadel, the American Visionary Art Museum.

Naturally, no math-art excursion could be complete without a visit to the Maryland Science Center, located in the bustling Inner Harbor. After all, in 2012 the latter provided the venue for Math Midway, a travelling interactive exhibit for popularizing mathematics and arts assembled by the National Museum of Mathematics in New York with the assistance of the Bridges director, George Hart (see http://mathmidway.org/). At Fort McHenry, birthplace of the American National Anthem, the sculptor William Duffy-known not only for his portrait of Francis Scott Key, but also for utilizing mathematical concepts in his artistic works-held a lecture for the 2012 Bridges conference participants. Following these events, in 2015 it became evident that Baltimore-aptly nicknamed "Charm City", and the home of Johns Hopkins, Edgar Allan Poe and Benjamin Banneker-continues to possess ample attractions for the world's largest math-art community.

From July 29-August 1, 2015, the University of Baltimore opened its doors to welcome Bridges. The conference's wide array of events was held at the John and Frances Angelos Law Center-the work of Boston's Behnisch Architekten and Baltimore's Ayers Saint Gross architectural offices-and the UB Student Center, designed by Murphy and Dittenhafer Architects. Since its opening in 2013, the John and Frances Angelos Law Center has taken its place as central Baltimore's main architectural landmark while also becoming the recipient of numerous architectural awards. Thanks to its carefully wrought, energy-efficient design, this structure is held as one of the most sustainable buildings in the USA today (Fig. 1).

Fabricated of concrete, glass and metal, the excitingly rhythmic, interlocked nature of the structure's checkered, L-shaped blocks creates the feeling that the viewer has been projected to a still-shot of a 3D Tetris match taking place in an urban square. Inside, the exterior's playful usage of forms is echoed in the columns and stairs soaring throughout the interior's heights. Surprising connections are created between the structure's separate areas with the help of stairways winding upward in graceful spirals or zig-zagging in jagged steps, bridges spanning the building's space in daring diagonals, as well as glass elevators, thereby allowing for quick and efficient passage between floors. The way in which larger spaces could be either be broken up or put together in new configurations proved particularly useful when organizing the complex events typical of the diverse program modules found at Bridges conferences. Placed as they were in the horizontally shifted and vertically spiraling modules extending up the building, single segments of the large-scale Bridges exhibit were able to resonate even more with the conference sections, workshops and community events held on different floors. The perfect places for 

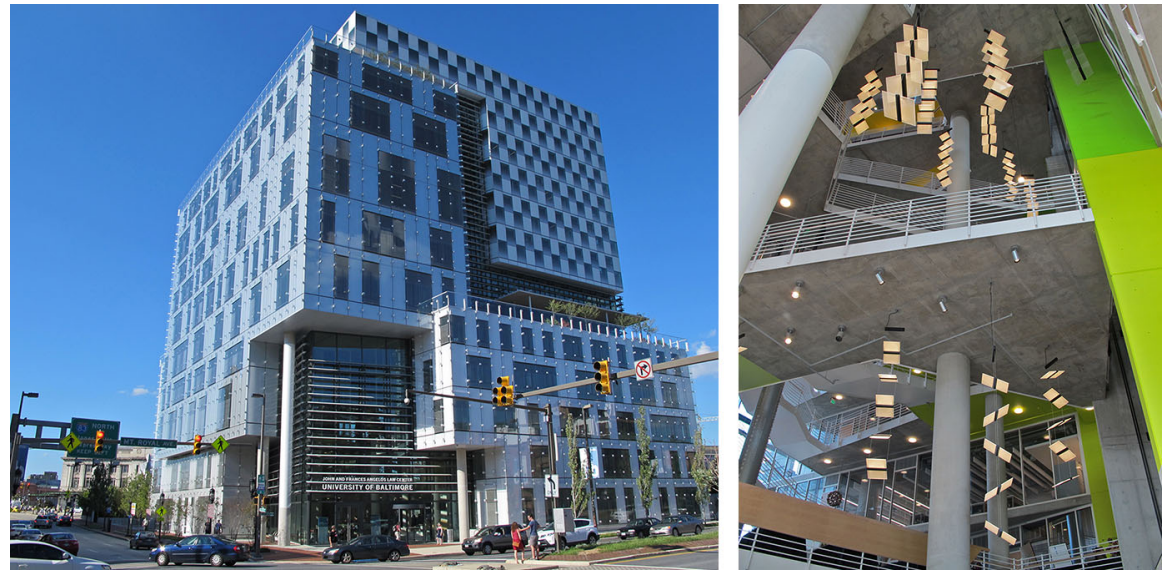

Fig. 1 Exterior (left) and interior (right) of the John and Frances Angelos Law Center. Photos by Carlo H. Séquin

exchanging ideas well beyond the time allotted for coffee breaks, the main hall and inner courtyard were also sites for spontaneously held math-art workshops.

In the academic program for Bridges Baltimore 2015, the list of plenary lecturers was honored to feature names such as that of the legendary mathematician, John $\mathrm{H}$. Conway. A distinguished scholar in many areas as well as the inventor of an independent approach to designing magic squares, Conway abandoned the formality of typical conference lectures in order to familiarize the Bridges community with the magic square depicted in Albrecht Dürer's engraving, Melancholia I. Siobhan Roberts, award-winning author and writer of Genius at Play (Roberts 2015a), a recently published biography tracing Conway's life and work, accompanied the scholar to the Bridges conference. Roberts offered the audience a description of the circumstances leading up to the birth of this novelistic biography, as well as sharing a few, lesser-known episodes from Conway's life in her Bridges lecture, "The Curious Creativity of John Horton Conway" (Roberts 2015b).

Taking her place at the podium for the third time before the Bridges community, Ingrid Daubechies held her lecture entitled "Math Helping Art Conservation". In addition to being the first female president of the International Mathematics Union, Daubechies also hosted the International Congress of Mathematicians (ICM) from 2011 to 2014 while simultaneously providing her patronage to the Bridges 2014 in Seoul, Korea. In his lecture, "The Arts of the Hidden", Alan C. Kay the father of the personal computer and many other developments in the history of information technology, analyzed the difficulties in visualizing how information is transferred within living organisms while also demonstrating this issue through a series of spectacular digital animations. A regular participant at Bridges conferences, cofounder of the internationally known beadwork design studio, beAd Infinitum (http:// www.beadinfinitum.com) and associate editor of the Journal of Mathematics and the Arts, Gwen Fisher's lecture, entitled "Highly Unlikely Triangles and Other Impossible Figures in Bead Weaving" (Fisher 2015) discussed how the math-art 
possibilities contained in bead-weaving can be exploited to depict and demonstrate a variety of visual paradoxes. Fisher also introduced the details of her sculptural and architectural project, the design and the production of the 25-foot high structure called Genie Bottle, created for the 2014 Burning Man Festival held in the Nevada desert and constructed with the help of friends (see http://gwenbeads.blogspot.hu/ 2014/04/the-genie-bottle.html and http://gwenbeads.blogspot.hu/2014/09/geniebottle-at-burning-man-2014.html). The Genie Bottle is decorated in patterns adapted from Eastern ornamentation and making use of geometric forms and mathematical formulae (Fig. 2).

The conference's program featured more than 100 lectures spanning a wide spectrum of topics including everything from explorations in artistic and mathematical connections in history and in different cultures, questions of implementing artistic and creative activities in the learning of mathematics, to the mathematical correlations in contemporary art. The Bridges 2015's Program Chair was Kelly Delp, responsible for coordinating the International Program Committee, comprised of over fifty experts. Delp also provided extensive reviews and editorial comments on submissions while simultaneously serving as chair of the regular papers' track. Douglas M. McKenna acted as chair of the short papers' track while receiving strong support from Carlo H. Séquin. For the first time in Bridges' history, 2015 marked the year when workshop submissions were reviewed by a full, special committee of reviewers, chaired by Craig S. Kaplan. This year, as always, the Conference Proceedings-edited by Kelly Delp, Craig S. Kaplan, Douglas McKenna, and Reza Sarhangi-are available on-line and can be browsed and downloaded for free at http://archive.bridgesmathart.org/2015/index.html.

150 artists submitted their works to the math-art exhibit, a heretofore unprecedented increase in participation. Similar to the wide variety displayed in conference lectures, many works utilized an incredible diversity of artistic media, including 2D and 3D digital prints, painting, beadwork, ceramics, wood, metal, quilting and folded paper. Robert Fathauer and Katie McCallum served as cocurators of this exhibition. The on-line catalog can be accessed for free at http:// gallery.bridgesmathart.org/exhibitions/2015-Bridges-Conference. Preceding the Bridges Conference, Chris Bartlett had organized a month-long gallery exhibition held at Towson University's College of Fine Arts Gallery.

Fig. 2 Genie Bottle at night at Burning Man Festival in 2014. The Genie Bottle was built by Struggletent with help from a grant from Burning Man. Gwen Fisher was the lead artist. Photo by Daniel Thornton

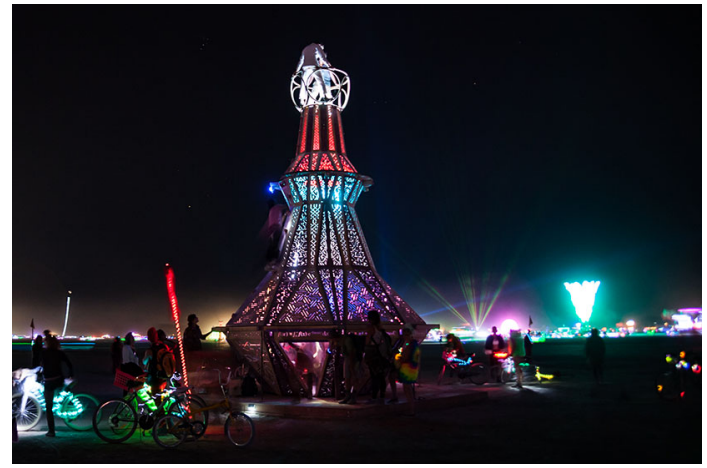


Conference participants were also able to cast their votes in four categories of works exhibited. The highly esteemed, "Best of Show" award went to the work Day, created by Eve Torrence, professor of mathematics as well as a future Program Chair for the 2016 Bridges Conference to be held in Finland. Constructed of yellow cardstock and created as a counterpart to her blue-toned piece, Night, Torrence's dodecahedron-like Day (Fig. 3) took paper-folding techniques utilized by Erik Demaine to a whole new level (see Demaine et al. 1999). In "The Most Innovative" category Louis Markoya's work, 3-Dimensional Fractal Chess Set with Menger Sponge Based Lenticular Board (Fig. 4) garnered great success. A former assistant to Salvador Dalí, Markoya combined fractal art with the kind of surreal vision inspired by Dalí and brought to life through the implementation of one of the most cutting-edge tools of our age, 3D printing. The exhibit's "Best Craftsmanship" award was undoubtedly deserved by Malcolm Tibbets's work, Pathways (Fig. 5). Tibbets was in fact inspired to create his first artistic experimentation through the work of George Hart, and has since developed his own, independent technique called "segmented woodturning", used to create extremely complex pieces of woodwork, such as the twelve interlocking wooden rings composing his awardwinning composition, Pathways. Finally, in the category of "Best Use of Mathematics," Jean Constant, painter and regular participant in Bridges exhibits, received the viewers' recognition for the work Cayley cubic \#4 (Fig. 6). Constant generated this piece while using MFO-Surfer software, whose application extends far beyond artistic utilities to include the type of educational and math-promotional possibilities thoroughly explored in the "Imaginary" open mathematics project (imaginary.org), spearheaded by the Mathematisches Forschungsinstitut in Oberwolfach, Germany.

The culmination of the conference's cultural events was without doubt The Mathematics of Being Human, a theatre production created by the University of Maryland faculty and students. This performance was held in the University of Baltimore's Student Center's Wright Theatre and a reception before the show was sponsored by the Mathematical Sciences Research Institute. The script was the

Fig. 3 Day by Eve Torrence

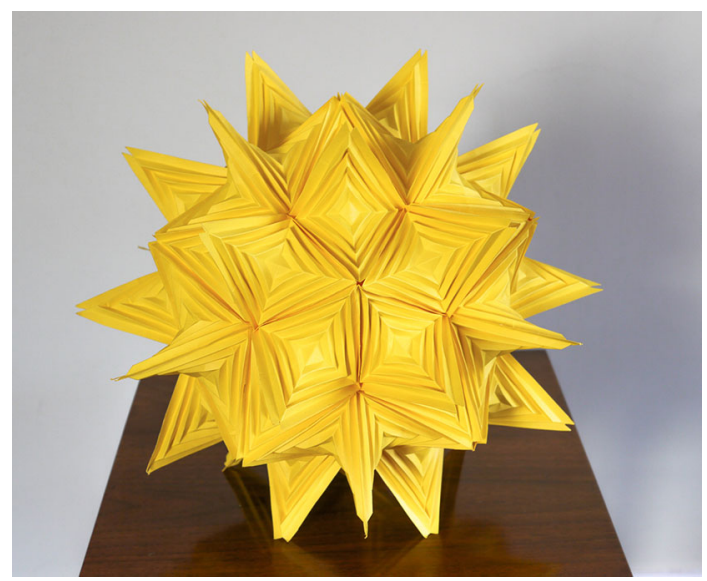




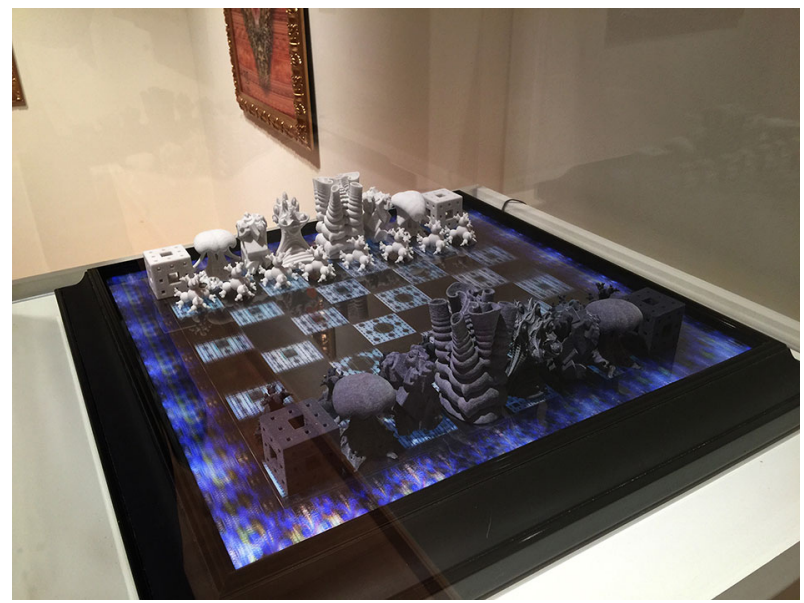

Fig. 4 3-Dimensional Fractal Chess Set with Menger Sponge based Lenticular Board by Louis Markoya

Fig. 5 Pathways by Malcolm Tibbets

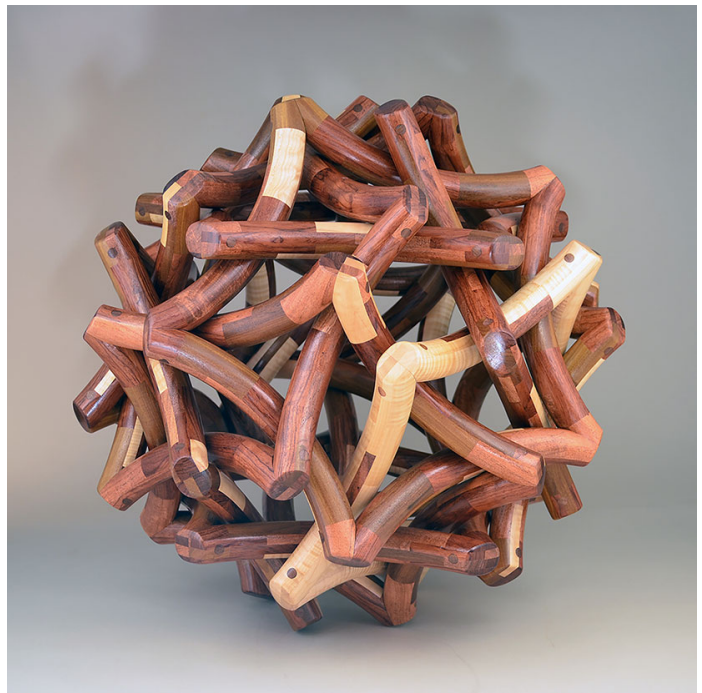

result of cooperation between the literary historian and dramaturg Michele Osherow, who combined forces with mathematician and novelist Manil Suri in order to further promote the power of inter- and transdisciplinary thinking and connections between mathematics and the arts. This joint production was put on stage by Alan Kreizenbeck. During this performance, the authors were played by themselves, allowing Bridges participants to revel in their skill as actors as well as authors. The play's basic plot weaves a situation familiar to many of those seated in the Bridges audience: two professors, one of literature and the other of mathematics, have been given the task of jointly creating a new course dedicated to exploring 
Fig. 6 Cayley cubic \#4 by Jean Constant

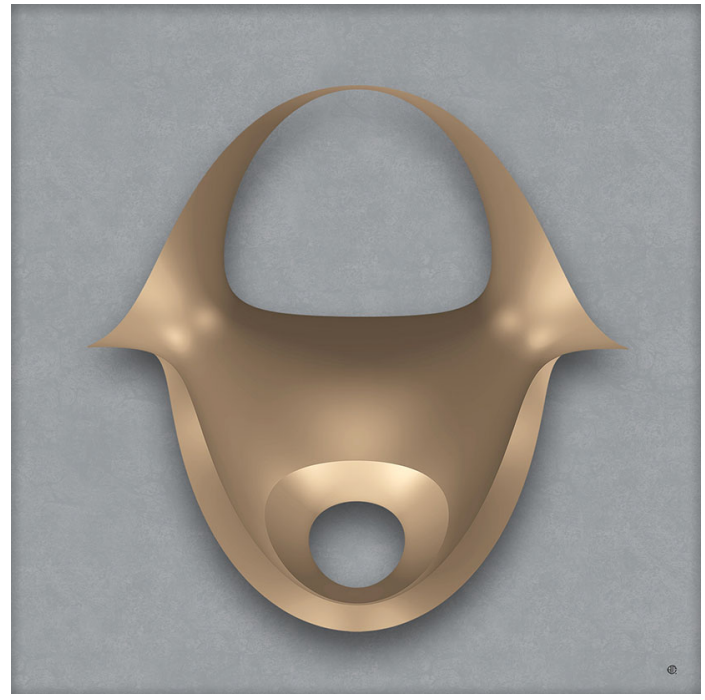

interdisciplinarity. In a credible, yet also scintillatingly humorous manner this play demonstrated how the professors (played by Michele Osherow and Manil Suri) and their students (played by Savannah Jo Chamberlain and Chaz Atkinson) were struggling in the beginning, but finally became able to move beyond the clichés and stereotypes surrounding the two fields. At the same time, the professional pitfalls and misunderstandings experienced throughout this process became the path leading to a spirit of cooperation best demonstrated in the birth of the theatre production placed on stage for the enjoyment and edification of all those present.

Within the framework of the conference's Family Day (www.familyday.hu), numerous math-art programs relevant to a wider audience-featuring two dozen workshops (Fig. 7a-c), an exhibit of children and youth math-art works coordinated by the international team of Jardin Galerie-New York and Experience Workshop Math-Art Movement, a short film festival of mathematical art curated by Robert Bosch, a poetry afternoon curated by Sarah Glaz and a theater performance by an amateur acting group gleaned from Bridges conference-goers and led by Steven Abbott-were also held. Among the most memorable productions were Tim and Tanya Chartier's pantomime performance, the Mimematics, as well as the Pythagorean Trio's math and dance premier, featuring the mathematician Karl Schaffer and the dancers Saki and Laurel Shastri.

The math-art excursions organized at the 2015 Bridges contained surprises even for those already familiar with Baltimore. Paul Espinosa, professor at Johns Hopkins University as well as curator of the library's exhibit, introduced visitors to the George Peabody Library, considered one of the most beautiful libraries in the world. After showing the library building constructed according to plans by Edmund G. Lind and Dr. Nathaniel H. Morison and first opened in 1878, Espinoza discussed different documents, books, and even fun gizmos, such as a zoetrope (a pre-film animation device), and all parts of the collection on display. The next leg of the trip 
Fig. 7 Math-art-education tools and activities at the Bridges 2015 Family Day: a The US Zometool; b the Korean 4D frame; $\mathbf{c}$ the Hungarian Polyuniverse. Photos: Kristóf Fenyvesi
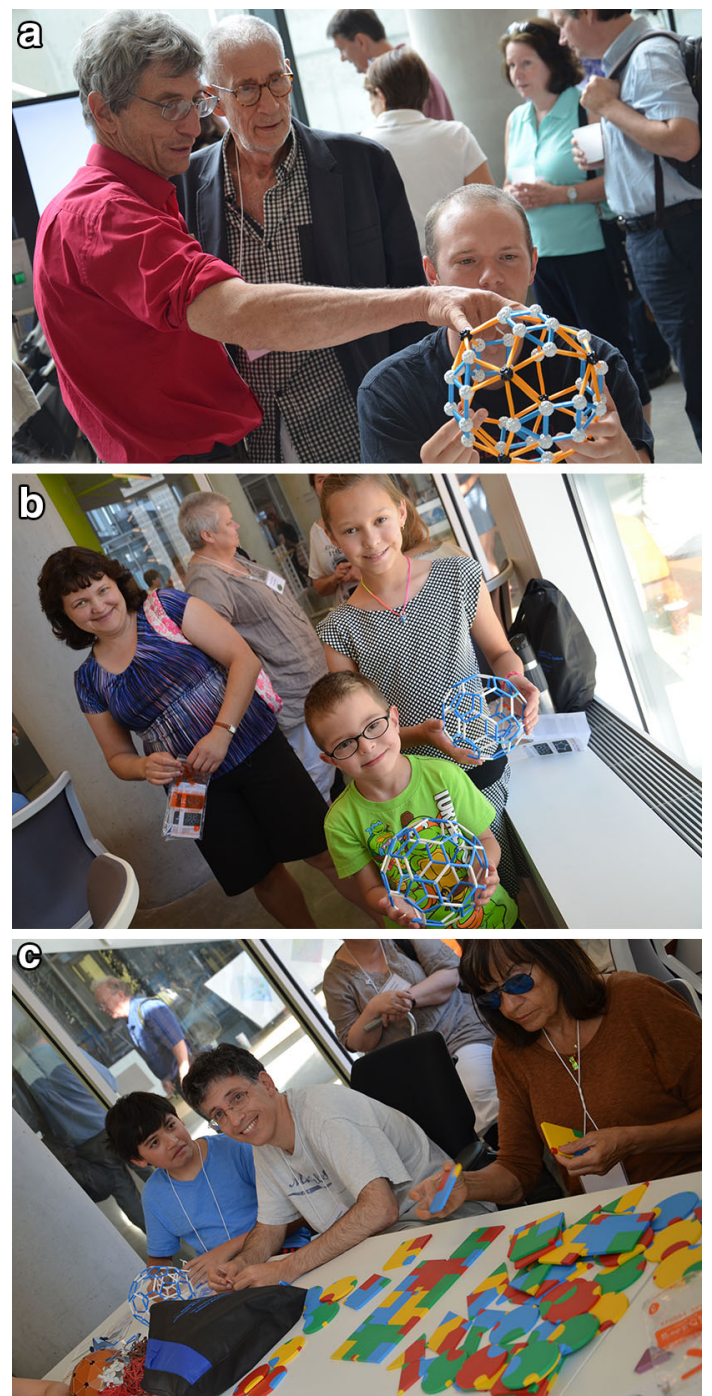

took Bridges participants to Washington D.C.'s Lincoln Memorial and various branches of the Smithsonian Museum.

The 2015 Bridges Baltimore concluded amidst a wealth of positive reactions and great successes. None of this would have been possible without Bridges Organization's committed president, Reza Sarhangi and the University of Baltimore, host to the Bridges 2015, or this institution's staff and faculty, including special thanks to the local conference organizer Sujan Shrestha. From the steamy summer heat of Baltimore, in 2016 the Bridges Conference will make its way to Finland, the most northern point ever explored by the Bridges community. Organized by the University of Jyväskylä, the unique programs offered by Bridges 
Finland 2016 can already be perused on the event's website: http://www. bridgesmathart.org/bridges-2016/.

\section{References}

Demaine, Erik D., Martin L. Demaine and Anna Lubiw. 1999. Polyhedral Sculptures with Hyperbolic Paraboloids. In Proceedings of the 2nd Annual Conference of BRIDGES: Mathematical Connections in Art, Music, and Science (BRIDGES'99), 91-100. Reza Sarhangi, ed. http:// archive.bridgesmathart.org/1999/bridges1999-91.pdf. Accessed 3 January 2015.

Fisher, Gwen. 2015. Highly Unlikely Triangles and Other Impossible Figures in Bead Weaving. In Proceedings of Bridges 2015: Mathematics, Music, Art, Architecture, Culture, 99-106. Kelly Delp, Craig S. Kaplan, Douglas McKenna, and Reza Sarhangi, eds. http://archive.bridgesmathart.org/ 2015/bridges2015-99.pdf. Accessed 3 January 2015.

Roberts, Siobhan. 2015a. Genius at Play: The Curious Mind of John Horton Conway. New York: Bloomsbury USA.

Roberts, Siobhan. 2015b. The Curious Creativity of John Horton Conway. In Proceedings of Bridges 2015: Mathematics, Music, Art, Architecture, Culture, 317-322. Kelly Delp, Craig S. Kaplan, Douglas McKenna, and Reza Sarhangi, eds. http://archive.bridgesmathart.org/2015/bridges2015317.pdf. Accessed 3 January 2015.

Kristóf Fenyvesi, Ph.D. is a researcher of contemporary culture at University of Jyväskylä's Department of Art and Culture Studies; member of Board of Directors and Director of Community Events at the world largest art and mathematics community, the Bridges Organization (www.bridgesmathart.org); chief executive officer of International Symmetry Association (www.symmetry.hu) and director of Experience Workshop-International Math-Art Movement for Experience-oriented Education of Mathematics (www. experienceworkshop.hu). His main areas of research are mathematical connections in arts, culture and education; STEAM integration; interdisciplinary aesthetics and philosophy. 